\title{
TTR
}

Traduction, terminologie, re?daction

\section{Hans J. Vermeer (1996). Die Welt, in der wir übersetzen. Drei translatologische Überlegungen zu Realität, Vergleich und Proze $\beta$. Heidelberg, TEXTconTEXT (Band 2)}

\section{Nadja Grbić et Michaela Wolf}

Volume 12, numéro 2, 2e semestre 1999

Poésie, cognition, traduction II - Autour d'un poème de W. H. Auden

Poetry, Cognition, Translation II — On a Poem by W. H. Auden

URI : https://id.erudit.org/iderudit/037382ar

DOI : https://doi.org/10.7202/037382ar

Aller au sommaire du numéro

Éditeur(s)

Association canadienne de traductologie

ISSN

0835-8443 (imprimé)

1708-2188 (numérique)

Découvrir la revue

Citer ce compte rendu

Grbić, N. \& Wolf, M. (1999). Compte rendu de [Hans J. Vermeer (1996). Die Welt, in der wir übersetzen. Drei translatologische Überlegungen zu Realität, Vergleich und Proze $\beta$. Heidelberg, TEXTconTEXT (Band 2)]. TTR, 12(2), 197-199.

https://doi.org/10.7202/037382ar d'utilisation que vous pouvez consulter en ligne.

https://apropos.erudit.org/fr/usagers/politique-dutilisation/ 
Hans J. Vermeer (1996). Die Welt, in der wir übersetzen. Drei translatologische Überlegungen zu Realität, Vergleich und Prozeß. Heidelberg, TEXTconTEXT (Band 2)

"Du bénéfice d'une théorie "

Dans sa publication, " Du bénéfice d'une théorie ", Vermeer pose la question des "fondements quasi philosophiques " d'une théorie fonctionnelle de la traduction et de son rôle possible dans la pratique et la didactique. Dans les premiers chapitres, il présente le point de vue scientifique, par exemple le rapport existant entre la théorie et l'empirie ou entre une orientation théorique et une orientation appliquée de la recherche. Comme Vermeer l'a montré avec sa théorie du skopos, sa 
conception épistémologique est actionnelle et relativiste. Il décrit ensuite les facteurs de l'agir traductologique, dont deux prémisses semblent être importantes. Premièrement, la traduction et l'interprétation ne consistent pas en la simple transmission dans une autre langue, mais dans le déplacement d'un continuum de mondes possibles vers un autre continuum de mondes possibles. Deuxièmement, la différence de perception est érigée en règle (c'est là une autre réflexion relativiste, la vérité étant « la conviction relativisée de quelqu'un dans une situation donnée ").

Vermeer consacre un long passage à la perception des phénomènes. En ce qui concerne la culture, il se réfère à la subjectivité, à la philosophie relativiste, ainsi qu'aux méthodes neurophysiologiques. Il en ressort un modèle d'interaction complexe (Vermeer a recours, d'un côté, à la notion de frame et, de l'autre, il utilise le terme " channel reduction " de Poyatos), qui se concrétisera dans l'action interculturelle.

Les traducteurs et traductrices ne sont que des partenaires dans un ensemble (système), dont la tâche consiste à réaliser - de façon optimale - le skopos imposé. En tant que joueurs et joueuses (expert/e/s), ils/elles sont censé/e/s reconnaître et maîtriser les jeux de leurs partenaires d'interaction ainsi que leur développement respectif. Cet aspect prescriptif du travail de Vermeer mène directement vers une didactique qu'il voit comme une mise en conscience d'un processus (d'interaction) holistique, et qui devrait contribuer à nous sortir de l'enseignement traditionnel et conventionnel de la langue et à nous diriger vers un enseignement plus complexe du comportement traductif.

\section{"Comparaison et comparabilité "}

Dans la seconde partie, "Comparaison et comparabilité ", Vermeer examine dans quelle mesure l'agir traductologique se fonde sur les comparaisons transculturelles. Il veut développer une « théorie de la comparativité $»$ à l'intention des traducteurs et interprètes parce que les deux activités représentent, selon lui, l'acte de comparer par excellence. Dans un premier temps, l'auteur examine les différentes approches de comparaison et de comparabilité dans des disciplines comme la linguistique, la littérature comparée, les sciences de la culture, la psychologie, etc., en essayant d'y appliquer les considérations théoriques de la culture, telles qu'il les a développées en compagnie de Heidrun Witte. Celles-ci contiennent une conception « dynamique » de la culture s'appuyant sur des modèles d'analyse qui relèvent du skopos. 
Vermer s'intéresse ici davantage aux questions spécifiques de la culture. Dans un second temps, et à l'aune de sa terminologie complexe, il analyse des modèles de comparaison intraculturelle, interculturelle et interindividuelle, dont le plus petit dénominateur commun est le skopos. Il manque à cette publication le rattachement plus ou moins prononcé de ses considérations aux approches traductologiques.

\section{«Le monde comme processus »}

D'abord la théorie du processus avancée par Vermeer dans la troisième partie ne se limite pas au processus de la traduction, mais elle englobe le contexte plus large des cultures. C'est seulement dans un deuxième temps que les différents modèles de sa théorie du processus seront présentés. L'auteur et le récepteur " sont " des processus, la traduction proprement dite ( " l'agir traductologique ») est un acte créateur, capable de se modifier selon sa dimension spatiale et temporelle. En conclusion, Vermeer offre sept " faits traductologiques ", dans lesquels il désigne certaines traductions comme des estimations momentanées d'un phénomène et où il propose l'individualisation comme processus de traduction. Dans le même temps, il reconnaît le processus qui concerne la valorisation ou la critique d'une traduction. Ce processus dépend du caractère modifiable de l'espace dans lequel la valorisation a lieu. 